\title{
ANALISIS PERBANDINGAN ROUTING OSPF PADA JARINGAN MPLS DAN TANPA MPLS MENGGUNAKAN GNS3
}

\author{
I Gede Juliantara Putra ${ }^{1}$, Pande Ketut Sudiarta ${ }^{2}$, I Made Arsa Suyadnya ${ }^{3}$ \\ ${ }^{123}$ Program Studi Teknik Elektro Fakultas Teknik Universitas Udayana \\ Email: igdjuliantaraputra@gmail.com ${ }^{1}$ sudiarta@unud.ac.id ${ }^{2}$ \\ arsa.suyadnya@unud.ac.id ${ }^{3}$
}

\begin{abstract}
Abstrak
Proses routing adalah proses pemilihan jalur paket data dari komputer sumber ke komputer tujuan. Suatu pengiriman paket data (routing) bekerja pada layer 3 OSI, akan tetapi terdapat suatu teknologi baru dalam pengiriman paket data pada layer 2,5 OSI yaitu MPLS. Oleh karena itu, dilakukan penelitian untuk mengetahui perbedaan routing paket data melalui jaringan MPLS dan tanpa MPLS. Metode yang digunakan dengan membangun simulasi jaringan menggunakan 12 router, 4 switch dan 4 vpcs pada emulator GNS3 dengan tiga perlakuan berbeda, yaitu: skema pengujian bitrate sejenis, bitrate tidak sejenis dan salah satu link pada interface terputus (disable) pada jaringan MPLS dan tanpa MPLS. Hasil pengujian tersebut menunjukkan bahwa tidak ada perbedaan rute paket data, hal ini dikarenakan penggunaan jaringan MPLS pada layer 2,5 OSI dalam proses pemilihan rute paket data akan mengikuti mekanisme routing OSPF pada layer 3 OSI.
\end{abstract}

Kata Kunci: Routing, OSPF, MPLS, GNS3

\section{Abstract}

The routing process is the process of selecting the packet data path from the source computer to the destination computer. A data packet routing works on layer 3 OSI, but there is a new technology in sending data packets on the $2.5 \mathrm{OSI}$ layer that is MPLS. Therefore, a study was conducted to determine the difference of routing data packets through the MPLS and without the MPLS networks. The method used was by building a network simulation using 12 routers, 4 switches and 4 vpcs on GNS3 emulator with three different treatments, namely: bitrate testing schemes, non-similar bitrate, and one of the links on the interface was disabled on the MPLS and without MPLS network. The test results indicate that there was no difference of packet data route, this was because the use of MPLS network on layer $2.5 \mathrm{OSI}$ in the route packet selection process will follow OSPF routing mechanism on layer 3 OSI.

Keywords: Routing, OSPF, MPLS, GNS3

\section{PENDAHULUAN}

Internet merupakan jaringan komputer yang terbentuk dari terhubungnya satu komputer dengan komputer lain. Pada pengiriman paket data dari satu komputer ke komputer lain dibutuhkan sebuah jalur/rute. Proses pemilihan jalur/rute paket data dari komputer sumber menuju komputer tujuan disebut routing [1].

Routing dalam pengiriman paket data dapat menggunakan jaringan berbasis IP dan jaringan MPLS. Pada jaringan berbasis MPLS memiliki kelebihan yaitu bersifat connection-oriented dan bekerja pada layer 2,5 OSI sedangkan pada jaringan berbasis IP bersifat connectionless dan bekerja pada layer 3 OSI [2].

Salah satu aspek terpenting dalam proses routing adalah protocol routing. OSPF merupakan salah satu protocol routing dan umum digunakan karena OSPF merupakan protocol berstandar terbuka, yaitu routing protocol ini bukan ciptaan dari vendor manapun, berarti siapapun dapat menggunakannya dan dimanapun routing protocol ini dapat diimplementasikan [3].

Pada penelitian ini akan diujikan bagaimana pengaruh penerapan jaringan MPLS sebagai forwarding paket data dalam memilih jalur/rute paket data dengan penera- 
pan jaringan tanpa MPLS menggunakan routing OSPF, sehingga nantinya diketahui bahwa pengiriman paket data pada jaringan $M P L S$ dengan tanpa MPLS berpengaruh atau tidak dengan digunakannya routing OSPF. Penelitian ini akan mengujikan jaringan MPLS dan tanpa MPLS menggunakan emulator Graphical Network Simulator (GNS3) dengan menggunakan tiga perlakuan berbeda.

\section{TINJAUAN PUSTAKA}

\subsection{Open System Interconnection}

Model referensi standar sering disebut dengan Open System Interconnection (OSI) seven-layer model atau model OSI tujuh layer. Model OSI sering digunakan untuk menjelaskan cara kerja jaringan komputer secara logika. Model OSI bukanlah sebuah protocol. Model OSI terdiri atas layer-layer atau lapisan-lapisan berjumlah tujuh buah. Ketujuh layer tersebut yaitu: Physical layer, Data link layer, Network Layer, Transport Layer, Session Layer, Presentation Layer, Aplikasi layer [4].

\subsection{Routing Protocol}

Routing Protocol merupakan salah satu komponen terpenting pada network TCP/IP dan routing protocol bekerja pada layer ketiga OSI Layer yaitu Network Layer. Routing Protocol dibagi menjadi dua bagian, yaitu Interior Routing Protocol (Interior Gateway Protocol) dan Exterior Routing Protocol (Exterior Gateway Protocol) [3]. Terdapat dua jenis routing protocol yaitu Static route dan Dynamic route [5].

\subsection{Open Shortest Path First}

OSPF (Open Shortest Path First) merupakan routing protocol Link State (LS) bersifat open-standard (non proprietary). OSPF dikembangkan menggunakan algoritma Dijkstra's Shortest Path First (SPF). OSPF dapat melakukan konvergensi secara cepat dan menentukan path terbaik berdasarkan cost terendah. Protocol jenis LS dapat mempelajari lebih banyak informasi tentang struktur network dibandingkan jenis protocol lain. Sehingga lebih banyak informasi dapat dipertukarkan antar sesama neighbor [3].

\subsection{Multi Protocol Label Switching \\ Multi Protocol Label Switch (MPLS) \\ merupakan suatu teknologi penyampaian}

paket pada jaringan backbone atau jaringan utama dan bekerja pada layer 2,5 OSI. MPLS didefiniskan oleh IETF sebagai arsitektur network untuk memadukan kelebihan circuit-switched dan packet-switched dan untuk memadukan mekanisme label swapping di layer 2 OSI dengan routing di layer 3 OSI untuk mempercepat pengiriman packet. Jaringan MPLS terdiri atas sirkit yaitu Label-Switched Path (LSP), dengan menghubungkan titik-titik disebut LabelSwitched Router (LSR). LSP dibentuk dengan suatu protocol persinyalan. Protocol ini menentukan forwarding berdasarkan label pada paket. Label pendek dan berukuran tetap mempercepat proses forwarding dan mempertinggi fleksibilitas pemilihan path. Hasilnya adalah network datagram bersifat lebih connectionoriented [2].

\subsection{Graphical Network Simulator 3}

Graphical Network Simulator 3 (GNS3) adalah sebuah program graphical network simulator atau simulasi jaringan grafis untuk mensimulasikan topologi jaringan dengan lebih kompleks dibandingkan dengan simulator lainnya. Program ini dapat dijalankan pada operating system, seperti Windows maupun Linux [6].

\section{METODELOGI PENELITIAN}

Penelitian ini menggunakan data primer bersumber dari hasil penelitian menggunakan 12 router, 4 switch dan 4 vpcs serta 2 Interface (Fast Ethernet \& Ethernet). Hasil pada penelitian adalah rute paket data pada tiga skema pengujian berbeda. Data sekunder diambil dari beberapa buku-buku referensi, jurnal, skripsi dan artikel-artikel terkait dari internet. Berikut adalah tahapan penelitian:

1. Mengkaji literatur-literatur untuk digunakan dalam melakukan konfigurasi.

2. Penerapan Skenario I, yaitu: penerapan routing OSPF pada jaringan tanpa MPLS menggunakan GNS3.

3. Penerapan Skenario II, yaitu: penerapan routing OSPF pada jaringan MPLS dengan menggunakan GNS3.

4. Melakukan analisis dari membandingkan rute paket data paket data pada bitrate sejenis, bitrate tidak sejenis dan apabila salah satu link pada interface terputus (disable) pada routing OSPF pada jaringan MPLS dan tanpa MPLS menggunakan GNS3. 
5. Membuat hasil analisis dari hasil rute paket data paket data pada bitrate sejenis, bitrate tidak sejenis dan apabila salah satu link pada interface terputus (disable) pada routing OSPF pada jaringan MPLS dan tanpa MPLS menggunakan GNS3.

6. Penulisan kesimpulan diperoleh berdasarkan data dari penelitian.

\subsection{Pengujian Skenario}

Penelitian ini menggunakan dua buah pengujian skenario menggunakan emulator GNS3. Pengujian skenario I yaitu membangun simulasi routing OSPF pada jaringan tanpa MPLS dan pengujian skenario II yaitu membangun simulasi routing OSPF pada jaringan MPLS. Penelitian ini menggunakan beberapa perangkat simulasi, diantaranya: 12 router, 4 switch, 4 vpcs (virtual personal computer simulator).

Pengujian dengan tiga skema berbeda pada skenario I dan skenario II, yaitu bitrate sejenis dilakukan dengan menerapkan interface fast-ethernet untuk menghubungkan seluruh perangkat jaringan, selanjutnya pada bitrate tidak sejenis dilakukan dengan menerapkan beberapa interface ethernet pada router area 0 (backbone area) seperti pada penghubung antara router $P 1$ dengan router $P 2$, router $P 2$ dengan router $P 3$ dengan router $P 4$ dan interface lainnya menggunakan fast-ethernet dan pada skema pengujian pada salah satu inteface terputus yaitu penerapan interface dilakukan sama seperti dengan skema bitrate tidak sejenis namun untuk membedakan adalah dengan memutus (disable) router penghubung antara router $P 1$ dengan router $P 4$.

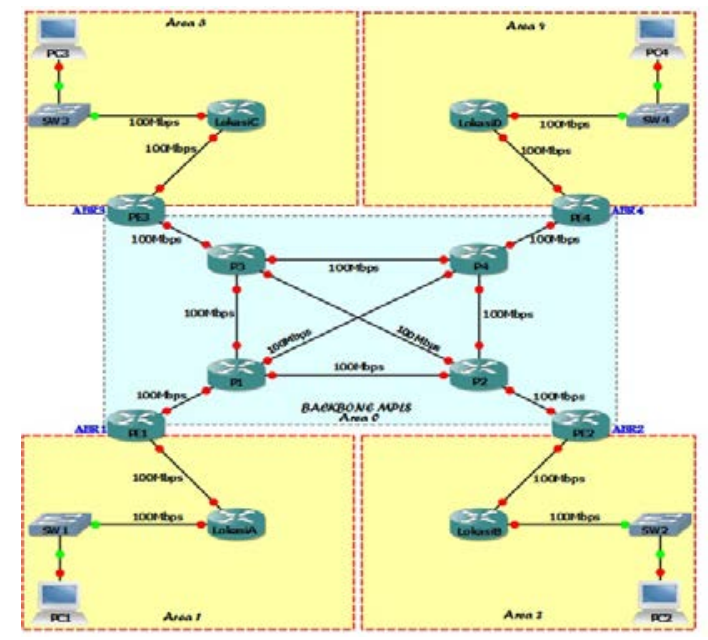

Gambar 1 Topologi Jaringan Pada Skenario I dan Skenario II

Topologi pada skenario I dan skenario II diterapkan sama yaitu terlihat pada Gambar 1. Pada jaringan tanpa MPLS, seluruh router pada topologi skenario I dan skenario II dikonfigurasikan dengan routing OSPF. Pada jaringan dengan MPLS, seluruh router pada areaO (backbone area) seperti area kotak biru pada Gambar 1 dikonfigurasikan dengan MPLS dan diterapkan pada skenario II, sedangkan pada skenario I tidak dilakukan konfigurasi MPLS pada areaO (backbone area) kotak biru pada Gambar 1

\subsubsection{Pengujian Skenario I}

Pada pengujian skenario I untuk menguji rute paket data dari komputer sumber ke komputer tujuan dilakukan tiga skema pengujian berbeda. Tahapan pengujian dimulai dengan mengkonfigurasikan perangkat jaringan yaitu router dan vpcs dengan konfigurasi IP Address, selanjutnya pada masing-masing router dikonfigurasikan dengan routing OSPF. Tahapan terakhir adalah menguji serta menganalisis jaringan tersebut dengan Ping dan Tracert pada command promt vpcs sumber ke vpcs tujuan.

\subsubsection{Pengujian Skenario II}

Pada pengujian skenario II untuk menguji rute paket data dari komputer sumber ke komputer tujuan dilakukan tiga skema pengujian berbeda. Tahapan pengujian dimulai dengan mengkonfigurasikan perangkat jaringan yaitu router dan vpcs dengan konfigurasi IP Address, selanjutnya pada masing-masing router dikonfigurasikan dengan routing OSPF dan khusus router pada areaO (backbone area) dikonfigurasikan dengan MPLS. Tahapan terakhir adalah menguji dan menganalisis jaringan tersebut dengan Ping dan Tracert pada command promt vpcs sumber ke vpcs tujuan.

\section{HASIL DAN PEMBAHASAN \\ 4.1 Penggunaan Perangkat}

Pada penggunaan perangkat dapat dibedakan menjadi dua yaitu, perangkat lunak (software) dan perangkat keras (hardware). Pada perangkat lunak digunakan Sistem Operasi Windows 10, 32 Bit dan Software GNS3 (Graphical Network Simulator) versi 1.3.13. Pada perangkat keras digunakan Notebook: Asus seri K45VD, Pro- 
cessor: Intel Core i3 2,4GHz, RAM: 2048 MB dan VGA: NVIDIA Geforce 610M 2GB.

\subsection{Konfigurasi IP}

Konfigurasi IP dibagi menjadi 2 tahapan yaitu, konfigurasi IP Loopback dan konfigurasi IP Address. Pemberian IP Loopback pada masing-masing router bertujuan untuk mengidentifikasi sebuah router dengan router lainnya dan berfungsi sebagai RID. Pada konfigurasi IP Address, pemberian IP pada skenario I dan skenario II dilakukan sama, akan tetapi perbedaannya terletak pada masingmasing skema pengujian karena menerapkan interface berbeda untuk setiap routernya.

\subsection{Konfigurasi Routing OSPF dan MPLS}

Pada tahapan konfigurasi routing OSPF, seluruh router pada penelitian ini akan dikonfigurasikan dengan routing OSPF baik pada pengujian skenario I maupun pengujian skenario II.

Setelah semua router dikonfigurasikan dengan routing OSPF sesuai areanya masing-masing, selanjutnya pada pengujian skenario II, router pada area 0 (backbone area) dikonfigurasikan dengan MPLS, sedangkan pada pengujian skenario I, router pada area 0 (backbone area) tidak dikonfigurasikan MPLS.

\subsection{Pengujian Rute Paket Data Pada Skenario I}

Rute paket data dapat diketahui dari $P C$ sumber yaitu $P C 1$ menuju $P C$ tujuan yaitu $P C 2, P C 3$ dan $P C 4$ dengan dilakukan menggunakan perintah "trace_ip-tujuan" pada command promt di $P C$ sumber melalui menu console pada GNS3. Pengujian untuk mengetahui rute paket data pada skenario I dilakukan tiga kali. Hasil pada pengujian rute paket data dengan skema pengujian bitrate sejenis dapat dilihat pada Tabel 1

Tabel 1 Hasil Trace Pada Penerapan Routing OSPF Pada Jaringan Tanpa MPLS (Skenario I) Dari PC1 Ke PC2, PC3, PC4 Skema Pengujian Bitrate Sejenis

\begin{tabular}{|c|c|c|c|}
\hline \multirow{3}{*}{ Hops } & \multicolumn{3}{|c|}{ HOST PENERIMA } \\
\cline { 2 - 4 } & $\begin{array}{c}\text { PC2 } \\
\text { (Interface) }\end{array}$ & $\begin{array}{c}\text { PC3 } \\
\text { (Interface) }\end{array}$ & $\begin{array}{c}\text { PC4 } \\
\text { (Interface) }\end{array}$ \\
\hline 1 & 192.168 .31 .1 & 192.168 .31 .1 & 192.168 .31 .1 \\
\hline 2 & 192.168 .21 .1 & 192.168 .21 .1 & 192.168 .21 .1 \\
\hline
\end{tabular}

\begin{tabular}{|c|c|c|c|}
\hline 3 & 192.168 .11 .1 & 192.168 .11 .1 & 192.168 .11 .1 \\
\hline 4 & 192.168 .1 .2 & 192.168 .4 .2 & 192.168 .5 .2 \\
\hline 5 & 192.168 .12 .2 & 192.168 .13 .2 & 192.168 .14 .2 \\
\hline 6 & 192.168 .22 .2 & 192.168 .23 .2 & 192.168 .24 .2 \\
\hline 7 & 192.168 .32 .2 & 192.168 .33 .2 & 192.168 .34 .2 \\
\hline
\end{tabular}

Pada skema pengujian bitrate tidak sejenis hasil pengujian rute paket data dapat dilihat pada Tabel 2 dan hasil pengujian pada skema pengujian salah satu interface terputus (disable) dapat dilihat pada Tabel 3.

Tabel 2 Hasil Trace Pada Penerapan Routing OSPF Pada Jaringan Tanpa MPLS (Skenario I) Dari PC1 Ke PC2, PC3, PC4 Skema Pengujian Bitrate Tidak Sejenis

\begin{tabular}{|c|c|c|c|}
\hline \multirow{2}{*}{ Hops } & \multicolumn{3}{|c|}{ HOST PENERIMA } \\
\cline { 2 - 4 } & $\begin{array}{c}\text { PC2 } \\
\text { (Interface) }\end{array}$ & $\begin{array}{c}\text { PC3 } \\
\text { (Interface) }\end{array}$ & $\begin{array}{c}\text { PC4 } \\
\text { (Interface) }\end{array}$ \\
\hline 1 & 192.168 .31 .1 & 192.168 .31 .1 & 192.168 .31 .1 \\
\hline 2 & 192.168 .21 .1 & 192.168 .21 .1 & 192.168 .21 .1 \\
\hline 3 & 192.168 .11 .1 & 192.168 .11 .1 & 192.168 .11 .1 \\
\hline 4 & 192.168 .5 .2 & 192.168 .4 .2 & 192.168 .5 .2 \\
\hline 5 & 192.168 .2 .1 & 192.168 .13 .2 & 192.168 .14 .2 \\
\hline 6 & 192.168 .12 .2 & 192.168 .23 .2 & 192.168 .24 .2 \\
\hline 7 & 192.168 .22 .2 & 192.168 .33 .2 & 192.168 .34 .2 \\
\hline 8 & 192.168 .32 .2 & - & - \\
\hline
\end{tabular}

Tabel 3 Hasil Trace Pada Penerapan Routing OSPF Pada Jaringan Tanpa MPLS (Skenario I) Dari PC1 Ke PC2, PC3, PC4 Skema Pengujian Salah Satu Interface Terputus (Disable)

\begin{tabular}{|c|c|c|c|}
\hline \multirow{3}{*}{ Hops } & \multicolumn{3}{|c|}{ HOST PENERIMA } \\
\cline { 2 - 4 } & $\begin{array}{c}\text { PC2 } \\
\text { (Interface) }\end{array}$ & $\begin{array}{c}\text { PC3 } \\
\text { (Interface) }\end{array}$ & $\begin{array}{c}\text { PC4 } \\
\text { (Interface) }\end{array}$ \\
\hline 1 & 192.168 .31 .1 & 192.168 .31 .1 & 192.168 .31 .1 \\
\hline 2 & 192.168 .21 .1 & 192.168 .21 .1 & 192.168 .21 .1 \\
\hline 3 & 192.168 .11 .1 & 192.168 .11 .1 & 192.168 .11 .1 \\
\hline 4 & 192.168 .1 .2 & 192.168 .4 .2 & 192.168 .4 .2 \\
\hline 5 & 192.168 .12 .2 & 192.168 .13 .2 & 192.168 .3 .2 \\
\hline 6 & 192.168 .22 .2 & 192.168 .23 .2 & 192.168 .14 .2 \\
\hline 7 & 192.168 .32 .2 & 192.168 .33 .2 & 192.168 .24 .2 \\
\hline 8 & - & - & 192.168 .34 .2 \\
\hline
\end{tabular}

\subsection{Pengujian Rute Paket Data Pada Skenario II}

Rute paket data pada skenario II dapat diketahui dengan menerapkan jaringan MLPS menggunakan routing OSPF seperti pada skenario I yaitu diujikan dari $P C$ sumber yaitu $P C 1$ menuju $P C$ tujuan yaitu $P C 2$, $P C 3$ dan PC4 dengan dilakukan menggunakan perintah "trace_ip-tujuan" pada command promt di $P C$ sumber melalui menu console pada GNS3. Pengujian untuk mengetahui rute paket data pada skenario II dilakukan tiga kali. Hasil pada skema pengujian bitrate sejenis dapat dilihat pada Tabel 4.

Tabel 4 Hasil Trace Pada Penerapan Routing OSPF Pada Jaringan Tanpa MPLS (Skenario II) 
Dari PC1 Ke PC2, PC3, PC4 Skema Pengujian Bitrate Sejenis

\begin{tabular}{|c|c|c|c|}
\hline \multirow{2}{*}{ Hops } & \multicolumn{3}{|c|}{ HOST PENERIMA } \\
\cline { 2 - 4 } & $\begin{array}{c}\text { PC2 } \\
\text { (Interface) }\end{array}$ & $\begin{array}{c}\text { PC3 } \\
\text { (Interface) }\end{array}$ & $\begin{array}{c}\text { PC4 } \\
\text { (Interface) }\end{array}$ \\
\hline 1 & 192.168 .31 .1 & 192.168 .31 .1 & 192.168 .31 .1 \\
\hline 2 & 192.168 .21 .1 & 192.168 .21 .1 & 192.168 .21 .1 \\
\hline 3 & 192.168 .11 .1 & 192.168 .11 .1 & 192.168 .11 .1 \\
\hline 4 & 192.168 .1 .2 & 192.168 .4 .2 & 192.168 .5 .2 \\
\hline 5 & 192.168 .12 .2 & 192.168 .13 .2 & 192.168 .14 .2 \\
\hline 6 & 192.168 .22 .2 & 192.168 .23 .2 & 192.168 .24 .2 \\
\hline 7 & 192.168 .32 .2 & 192.168 .33 .2 & 192.168 .34 .2 \\
\hline
\end{tabular}

Pada skema pengujian bitrate tidak sejenis hasil pengujian rute paket data dapat dilihat pada Tabel 5 dan hasil pengujian rute paket data pada skema pengujian salah satu interface terputus (disable) dapat dilihat pada Tabel 6.

Tabel 5 Hasil Trace Pada Penerapan Routing OSPF Pada Jaringan Tanpa MPLS (Skenario II) Dari PC1 Ke PC2, PC3, PC4 Skema Pengujian Bitrate Tidak Sejenis

\begin{tabular}{|c|c|c|c|}
\hline \multirow{2}{*}{ Hops } & \multicolumn{3}{|c|}{ HOST PENERIMA } \\
\cline { 2 - 4 } & $\begin{array}{c}\text { PC2 } \\
\text { (Interface) }\end{array}$ & $\begin{array}{c}\text { PC3 } \\
\text { (Interface) }\end{array}$ & $\begin{array}{c}\text { PC4 } \\
\text { (Interface) }\end{array}$ \\
\hline 1 & 192.168 .31 .1 & 192.168 .31 .1 & 192.168 .31 .1 \\
\hline 2 & 192.168 .21 .1 & 192.168 .21 .1 & 192.168 .21 .1 \\
\hline 3 & 192.168 .11 .1 & 192.168 .11 .1 & 192.168 .11 .1 \\
\hline 4 & 192.168 .5 .2 & 192.168 .4 .2 & 192.168 .5 .2 \\
\hline 5 & 192.168 .2 .1 & 192.168 .13 .2 & 192.168 .14 .2 \\
\hline 6 & 192.168 .12 .2 & 192.168 .23 .2 & 192.168 .24 .2 \\
\hline 7 & 192.168 .22 .2 & 192.168 .33 .2 & 192.168 .34 .2 \\
\hline 8 & 192.168 .32 .2 & - & - \\
\hline
\end{tabular}

Tabel 6 Hasil Trace Pada Penerapan Routing OSPF Pada Jaringan Tanpa MPLS (Skenario II) Dari PC1 Ke PC2, PC3, PC4 Skema Pengujian Salah Satu Interface Terputus (Disable)

\begin{tabular}{|c|c|c|c|}
\hline \multirow{3}{*}{ Hops } & \multicolumn{3}{|c|}{ HOST PENERIMA } \\
\cline { 2 - 4 } & $\begin{array}{c}\text { PC2 } \\
\text { (Interface) }\end{array}$ & $\begin{array}{c}\text { PC3 } \\
\text { (Interface) }\end{array}$ & $\begin{array}{c}\text { PC4 } \\
\text { (Interface) }\end{array}$ \\
\hline 1 & 192.168 .31 .1 & 192.168 .31 .1 & 192.168 .31 .1 \\
\hline 2 & 192.168 .21 .1 & 192.168 .21 .1 & 192.168 .21 .1 \\
\hline 3 & 192.168 .11 .1 & 192.168 .11 .1 & 192.168 .11 .1 \\
\hline 4 & 192.168 .1 .2 & 192.168 .4 .2 & 192.168 .4 .2 \\
\hline 5 & 192.168 .12 .2 & 192.168 .13 .2 & 192.168 .3 .2 \\
\hline 6 & 192.168 .22 .2 & 192.168 .23 .2 & 192.168 .14 .2 \\
\hline 7 & 192.168 .32 .2 & 192.168 .33 .2 & 192.168 .24 .2 \\
\hline 8 & - & - & 192.168 .34 .2 \\
\hline
\end{tabular}

\subsection{Hasil Perbandingan Rute Paket Data Pada Skenario I dan Ske- nario II}

Pada pengujian rute paket data pada skenario I dan skenario II didapatkan hasil rute paket data dengan tiga skema pengujian berbeda tersebut adalah sama. Hasil perbandingan rute untuk jalur paket data dari $P C$ pengirim yaitu $P C 1$ pada area1 menuju $P C$ penerima pada area lainnya seperti PC1 menuju PC2 ditunjukkan dengan garis (line) berwarna merah, $P C 1$ menuju $P C 3$ ditunjukkan dengan garis (line) berwarna ungu, $P C 1$ menuju $P C 4$ ditunjukkan dengan garis (line) berwarna hijau.

Hasil perbandingan rute paket data pada bitrate sejenis menunjukkan tidak ada perbedaan rute paket data dari komputer sumber menuju komputer tujuan pada skenario I maupun pada skenario II dengan hasil perbandingan tersebut terlihat pada Gambar 2.

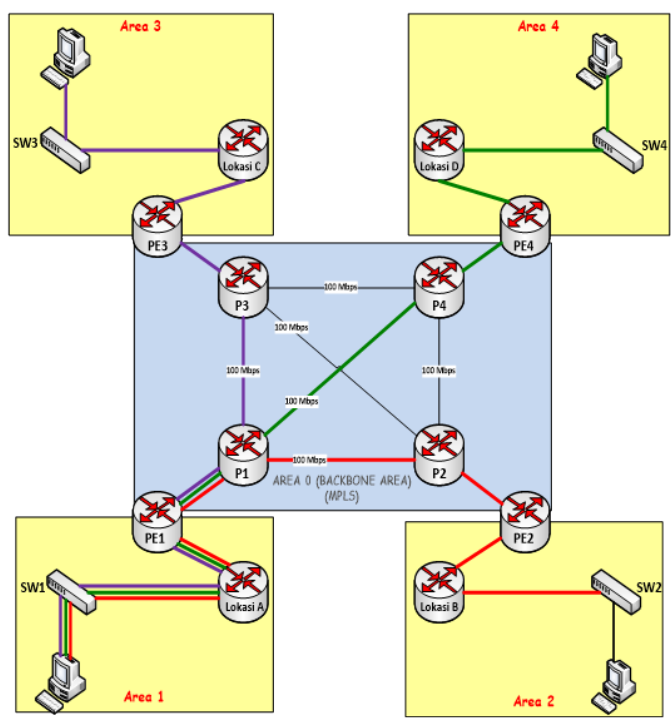

Gambar 2 Perbandingan Trace Pada Skenario I dan Skenario II Skema Pengujian Bitrate Sejenis

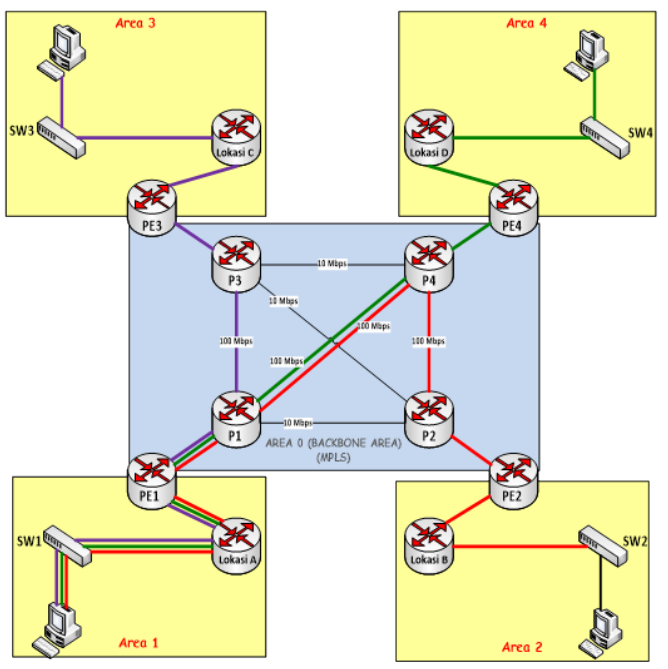

Gambar 3 Perbandingan Trace Pada Skenario I dan Skenario II Skema Pengujian Bitrate Tidak Sejenis

Hasil perbandingan rute paket data pada bitrate tidak sejenis menunjukkan tidak ada perbedaan rute paket data dari komputer sumber menuju komputer tujuan 
pada skenario I maupun pada skenario II dengan hasil perbandingan tersebut terlihat pada Gambar 3.

Hasil perbandingan rute paket data pada salah satu link pada interface terputus (disable) menunjukkan tidak ada perbedaan rute paket data dari komputer sumber menuju komputer tujuan pada skenario I maupun pada skenario II dengan hasil perbandingan tersebut terlihat pada Gambar 4.

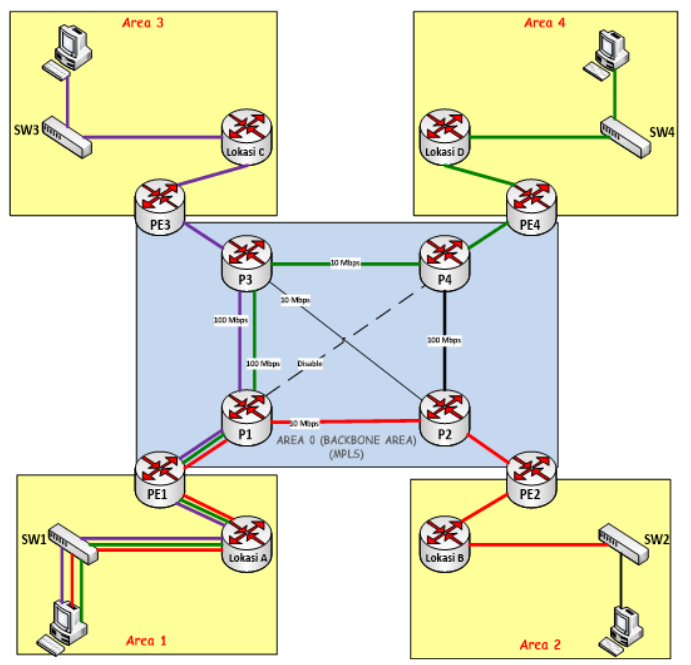

Gambar 4 Perbandingan Trace Pada Skenario I dan Skenario II Pada Skema Pengujian Salah Satu Interface Terputus (Disable)

Hasil pengujian dengan tiga skema pengujian pada skenario I maupun pada skenario II dapat disimpulkan bahwa, routing OSPF memilih jalur terbaiknya dengan menggunakan metric "Cost". Hasil dari rute pengiriman paket data pada MPLS dengan tiga skema pengujian berbeda hasilnya akan sama seperti pada rute pengiriman paket data routing OSPF tanpa MPLS karena menurut OSI Layer, pemilihan path terjadi pada layer 3 (network layer) dimana routing OSPF berada pada layer 3 dan MPLS berada pada layer 2,5 (antara datalink layer \& network layer). Jadi MPLS akan mengikuti path dari routing OSPF. Begitu juga dengan pada skema salah satu link terputus, routing OSPF akan tetap memilih path. Apabila path telah didapatkan selanjutnya MPLS akan memilih router untuk dijadikan Ingress dan Engress.

\section{SIMPULAN DAN SARAN}

\subsection{Simpulan}

Hasil kesimpulan pada penelitian ini adalah sebagai berikut:
1. Rute pengiriman paket data pada MPLS dengan tiga skema pengujian berbeda hasilnya akan sama seperti pada rute pengiriman paket data routing OSPF tanpa MPLS karena menurut OSI Layer, pemilihan path terjadi pada layer 3 (network layer) dimana routing OSPF berada pada layer 3 dan MPLS berada pada layer 2,5 (antara datalink layer \& network layer). Jadi, MPLS akan mengikuti path dari routing OSPF. Begitu juga dengan pada skema salah satu link terputus (disable), routing OSPF akan tetap memilih path. Apabila path sudah didapatkan selanjutnya MPLS akan memilih router untuk dijadikan Ingress dan Engress. Hal tersebut karena MPLS berada pada layer 2,5 OSI tidak akan memberikan pengaruh terhadap proses routing paket data.

2. Hasil analisis skenario perbandingan routing OSPF pada jaringan tanpa MPLS dan pada jaringan dengan MPLS dimana menggunakan skema bitrate sejenis, pemilihan rute paket data ditentukan dari keputusan routing dengan melewati router terdekat menuju host tujuan karena pada bitrate sejenis nilai cost didapatkan dari kalkulasi dengan seluruh bitrate bernilai sama.

3. Hasil analisis skenario perbandingan routing OSPF pada jaringan tanpa $M P L S$ dan pada jaringan dengan MPLS dimana menggunakan skema bitrate tidak sejenis, pemilihan rute paket data ditentukan dari keputusan routing dengan memilih bitrate terbesar karena bernilai cost rendah dengan hasil dari kalkulasi bitrate pada interface yang dilalui walaupun harus melewati beberapa router tetangga.

4. Hasil analisis skenario perbandingan routing OSPF pada jaringan tanpa MPLS dan pada jaringan dengan MPLS dimana menggunakan skema salah satu link terputus (disable) dengan bitrate tidak sejenis, pemilihan rute paket data ditentukan dari keputusan routing dengan menunggu router tetangga hingga adjacency ketika link telah terputus (disable) dan memilih bitrate terbesar karena bernilai cost rendah dengan hasil dari kalkulasi bitrate pada interface yang dilalui walaupun harus melewati beberapa router tetangga. 


\subsection{Saran}

Penelitian ini masih dalam tingkatan virtual atau simulasi, sehingga nantinya dapat atau perlu dilakukan penelitian menggunakan perangkat jaringan nyata.

\section{DAFTAR PUSTAKA}

[1] K. Nugroho, Router Cisco \& Mikrotik. Bandung: Informatika, 2016.

[2] L. D. Ghein, MPLS Fundamentals. Indianapolis: Cisco Press, 2007.

[3] I. Sofana, CISCO CCNP dan Jaringan Komputer. Bandung: Informatika, 2012.

[4] I. Sofana, CISCO CCNA \& Jaringan Komputer. Bandung: Informatika, 2014.

[5] M. Syafrizal, Pengantar Jaringan Komputer. Yogyakarta: Andi, 2008.

[6] J. Saputro, Praktikum CCNA di Komputer sendiri menggunakan GNS3. Jakarta: Mediakita, 2010. 